\title{
ARTICLE
}

\section{THE EFFICIENCY FORECAST OF TRILATERAL TRANSIT TRANSPORTATION OF ECONOMIC CORRIDOR}

\section{Zolboo Gansukh*}

School of Economics and Management, Yanshan University, Qinhuangdao city, Hebei province, China

\begin{abstract}
The development basis of a country is human capital which follows the transportation and infrastructure issues. In particular, landlocked countries with fewer neighbours ought to create transit transportations with its bordering countries that could help to reduce transportation costs, develop economies, transportation and tourism with neighbours, as well as promote regional economic relations and cooperation. An efficient transit transport is vital for landlocked states. Due to the lack of access to seaports, transit transportation is a unique way to connect with the neighbouring countries. Mongolia's geographical location, the rapid development of the mining and energy sectors are critically important for connecting with the "New Silk Road", the "Development Road National Programme" (former Steppe Road) and the "Eurasian Transportation Corridor". This paper is an attempt to forecast the efficiency of transit transport between Mongolia, China and Russia. The article focuses on the prerequisites for the development of the methodology for measuring the transit transport performance. Mongolia-China-Russia economic corridor marks a watershed in intensifying trilateral cooperation between Mongolia, China and Russia, which would not only create favorable conditions for furthering trilateral cooperation, but also promoting regional economic cooperation. Therefore, the paper has used Mongolian Railway statistical data of 2017 to provide efficiency analysis of the central railway system. A total of four types of railway transportation is carried out in Mongolia and transit transportation is relatively efficient. The efficiency calculation and performance of transport system of Mongolia were measured using the Data Envelopment Analysis.
\end{abstract}

Keywords: Economic corridor; data envelopment analysis; efficiency; transit transportation; railway;

\section{INTRODUCTION}

The road leads to the destination. It is difficult to imagine the development of the country without the road infrastructure. L. Gurjav had emphasized that the future of Mongolia and its economic potential will directly depend on the manner in which the driving force will be steered by using the most effective way of growth [1]. One of the key challenges of the country's economic policy in the present globalizing world is transportation. All neighbouring countries are a crucial source for the country's trade and economic development. The geopolitical location of Mongolia is highly attractive 
to its neighbouring countries. Mongolia is sandwiched between China and Russia without any access to seaport. There are 37 land-locked countries in the world [2]. The only access sea is by passing through the transit states.

Thus, we mainly focused on the efficiency estimation of transit transport of Economic Corridor and its impact other sectors. The purpose of the study is to understand the benefits, opportunities and potential risks of the trilateral Economic Corridor, based on the Belt and Road Initiative. Nowadays, international transportation, especially transit transportations, make it possible to promote external and internal relations of these countries. In June 2016, China, Russia and Mongolia inked a development plan to build an economic corridor linking the three neighbours, pledging to boost transportation connectivity and economic cooperation in the border regions [3], which could have a positive impact on promoting trade and economy, cultural exchange, transit transportation and tourism.

Some researchers agree that "Economic corridors are anchored in transport corridors, and international experience suggests that the higher the level of connectivity within and across countries, the higher the level of economic growth." [4]. The purpose of transportation development and improvement ought to fit into regional networking and better choice of its needs for the countries concerned [5]. The trilateral Economic Corridor not only deals with transport and customs issues though, it could perhaps extend to agriculture, tourism, emergency preparedness, and many other sectors. Once, Schwab commented about the Belt and Road initiative which respects the differences between countries and their different paths of development, not imposing a specific plan or ideological framework, but seeking to create common ground for cooperation and mutual benefit [6].

Transport corridors include the major road transportation complexes that connect countries focused primarily on international freight and freight routes, and mainly involving several types of transport and are technically wellequipped. It can also be understood as a space for intensifying specific efforts. An economic corridor is a geographical area that brings together multilateral economic activities. The corridor factor is important in the relationship between the three countries, which has now been upgraded to a comprehensive strategic partnership [7]. With the development of transit transportation in the Western and Eastern regions, trade routes will help promote tourism and the development of the region.

The current situation of the railway transit transportation

The construction of railway transportation is a budget-intensive venture. Railway transport is more significant [8] than other types of transportation as large volumes of freights and large number of passengers are transported one point to their final destination. Although more than 70 percent of the country's territory is mountainous does not mean that the construction and development of railway transportation are not feasible. What's extremely important is to implement the 32 projects [9], [10] that were signed in Dushanbe, Tajikistan; one of the key projects among them is the construction of the Eastern Region Railway Transit Transportation (Eastern Corridor). The main center of the Eastern region is Dornod aimag (province), which was established in 1931 with a total area of 122 [8] thousand square kilometers. To the north, Dornod province borders with the Chita Oblast of the Russian Federation and to the east, it borders with the People's Republic of China. A 238 kilometer long railway line already exists, which connects Dornod province and Chita Oblast, Zabaykalsky Krai. In our study, we focused on efficiency evaluation in the rail freight transport based on the available official statistical data. 


\section{MATERIALS AND METHODS}

Data Envelopment Analysis (DEA) is a method to empirically measure productive efficiency of decision making units by using single or multiple inputs and outputs developed on linear programming [11]. DEA was firt put forward by Charned et al in 1978 [12] and it can be applied apply in many sectors such as services, industrial, educational, financial sector etc.

The basic efficiency calculation equation of DEA is:

$$
\frac{\text { Input }}{\text { output }}
$$

This equation is the most widely used method for estimating efficiency, productivity and performance. Depending on the scope of the analysis, the DEA is designed as follows [12]:

1. Single input and single output
2. Multiple inputs and single output

3. Single input and multiple outputs

4. Multiple inputs and multiple output

For the given input and output variables, DEA measures a comprehensive calculation of performance and efficiency for each Decision Making Unit (DMU). For the input, it refers to income, human capital, and material that belong to the Decision Making Unit in which the decision-making process is to be carried out. For the output, it depends on the outflow of time, cost, or cost spent on the item, the researcher concerned and decide on the coverage. According to some researchers (Berg, 2010), there is no inequality in inputs and diffusion, but this analysis is advantageous for any organization to review its outcomes and to look into what is to be considered.

The DEA model mathematically expressed [11], [12]:

$$
\operatorname{Max} h_{k}(u, v)=\frac{\sum_{r=1}^{s} u_{r} y_{r k}}{\sum_{i=1}^{m} v_{i} x_{i k} \ldots} \mathrm{k}=1,2, \ldots, \mathrm{n}
$$

Subject to:

$$
\begin{aligned}
& \frac{\sum_{r=1}^{s} u_{r} y_{r j}}{\sum_{i=1}^{m} v_{i} x_{i j} \ldots} \leq 1, j=1,2, \ldots, n \\
& u_{r} \geq 0, r=1,2, \ldots, s \\
& v_{r} \geq 0, i=1,2, \ldots, m
\end{aligned}
$$

where:

$\mathrm{h}_{\mathrm{k}}$ - is the relative efficiency unit $k$

$\mathrm{y}_{\mathrm{rj}}$ - is the amount of output $\mathrm{r}$ generated by unit $k$

$\mathrm{x}_{\mathrm{ij}}$ - is the amount of input $\mathrm{i}$ generated by unit $j$

$\mathrm{n}$ - is the number of DMU under efficiency calculation

$\mathrm{m}-$ is the number of input

$\mathrm{s}-$ is the number of output

$u_{r}$ - is the weight for output

$\mathrm{v}_{\mathrm{i}}$ - is the weight for input 
The equations from 2-5 determines that $\mathrm{n}$ times are required to measure the relative efficiency of each DMU. Mathematically, the non-negative constraints in equation 4 and 5 are not sufficient for fractional equation 3 which have a value greater than zero [11], [12]. Thus, all the weights for inputs and outputs assumed as non-zero values. This linear fractional function programming, also called CCR (CCR stands for the abbreviation of the names - Charnes, Cooper and Rhodes) ratio model. The DEA also has some limitations.
It creates a separate linear programme for each DMU and could be computationally an intensive work. Furthermore, all efficient units are assigned with the same score 1.00 , thus their further ranking is not possible. In view of this, some researchers such as Petersen and Andersen have proposed [13] for allowing efficient unit to attribute a score greater than 1.000 by dropping the constraints that bind the score of the evaluated unit $\mathrm{k}$, explicitly, the primary problem of unit $\mathrm{k}$, which is formulated in the following equations 6-10.

$$
\operatorname{Max} h_{k}(u, v)=\sum_{r=1}^{s} u r y \mathrm{rk}
$$

Subject to:

$$
\begin{aligned}
& \sum_{r=1}^{s}: \ldots: v_{i} x_{i k}=1 \\
& \sum_{r=1}^{s} u_{r} y_{r j}-\sum_{i=1}^{m} v_{i j} x_{i j} \leq 0, j=1,2, \ldots, n, j \neq k \\
& u_{r} \geq 0, r=1,2, \ldots, s \\
& v_{i} \geq 0, i=1,2, \ldots, m
\end{aligned}
$$

Here, $\mathrm{k}^{\text {th }}$ DMU is relatively efficient if the value of $h_{k}$ in the objective function is equal to 1 and if the $h_{k}$ is less than 1 , then relative $k^{\text {th }}$ DMU will be inefficient. DEA model could be used for improving the performance by

\section{RESULTS AND DISCUSSION}

The total length of central (currently the only one) railroad is 2100 kilometers and it connects Beijing-Ulaanbaatar-Ulan-Ude, [15] primarily handling export, import, domestic and transit freight transport.

We have analyzed the efficiency of 4 types of railway freight transportations by using the 2017 statistics of the Mongolian Railways. These four types of freight transportations have been classified into four Decision Making Units as follows: increasing the desirable output and decreasing undesirable outputs. Zhu et al, consider that the DEA method [14] can be applied when some inputs need to be increased to improve performance.
Decision Making Unit 1: Domestic freight transportation

Decision Making Unit 2: Export freight transportation

Decision Making Unit 3: Import freight transportation

Decision Making Unit 4: Transit freight transportation 


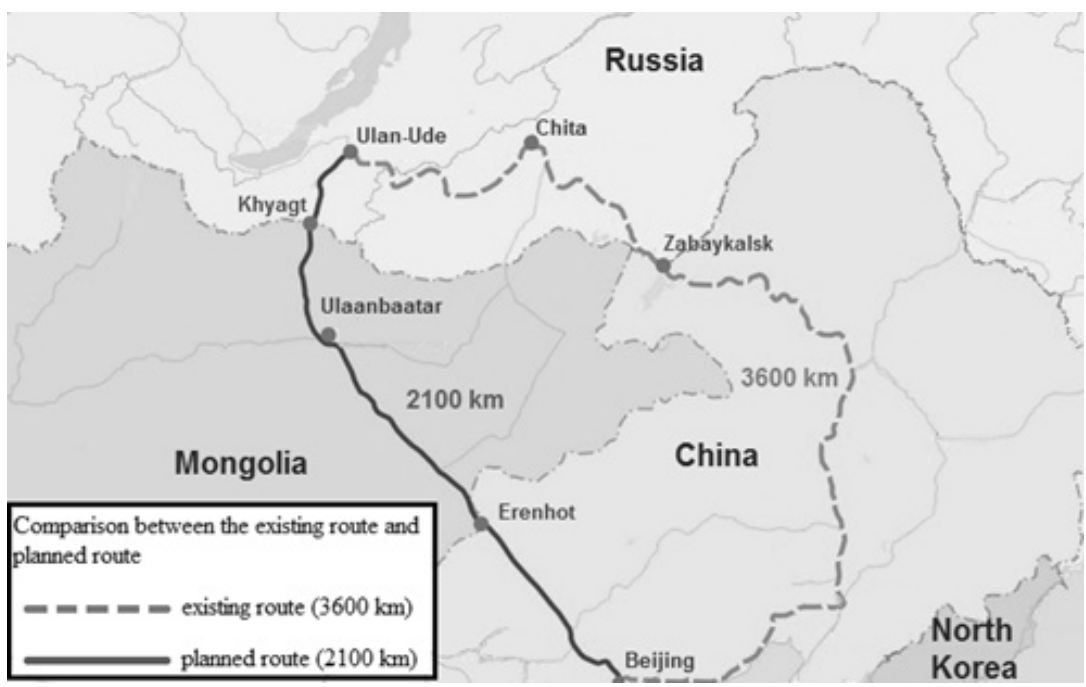

Figure 1: Length of central railway corridor

Source: www.mrtd.gov.mn

There are many factors related to the performance of railway freight transportation, however, for the input we have decided on "transported freight 1 ", which refers to the number of wagons for goods transportation, and number of employees. For the output, we have selected "freight turnover" 2 ", which measures freight ton-kilometers. The selection of input and output was based with due consideration of the study done by Hilmola [16]. We have collected data of input and output from the Online Platform of the National Statistical Office of Mongolia.

Table 1: Initial data of Mongolian Railway freight transport, year 2017

\begin{tabular}{|c|l|c|c|c|c|}
\hline & & Domestic & Export & Import & Transit \\
\hline Input $=\mathrm{x}$ & Transported freight in thousand tons & $2,473.5$ & $6,417.6$ & $1,171.1$ & 3,431 \\
\hline Output $=\mathrm{y}$ & Freight turnover, million ton kilometer & $9,484.6$ & 7886.8 & 2302.7 & 3091 \\
\hline
\end{tabular}

Data source: www.1212.mn (National Statistical Office)

Based on the data, the analysis presented here is based on "Open Source DEA" program ${ }^{3}$ to get a precise result.

1. Transported freight expresses the total freight for a specified distance. The freight loads are diverse, depending on the nature of the branches, and the burden, thus, divided into categories according to their characteristics. All tonnage of freight shall be expressed in tons regardless of the unit of measure. - National Statistical Office of Mongolia and Transport Statistics 2008.

2. One unit carries one ton of freight transport within one kilometer. The amount of freight transport and freight shall be calculated by the type of freight for each type of transport. The freight turnover is expressed in tons.

3. http://opensourcedea.org/ 
Table 2: Efficiency calculation through DEA programme

\begin{tabular}{|c|l|c|c|c|}
\hline DMU No & \multicolumn{1}{|c|}{ DMU Name } & Efficiency & $\begin{array}{c}\text { Weighted } \\
\text { Input }\end{array}$ & $\begin{array}{c}\text { Weighted } \\
\text { Output }\end{array}$ \\
\hline 1 & Domestic freight transportation & 0.234948 & 1 & 0.385424 \\
\hline 2 & Export freight transportation & 0.733078 & 0.831537 & 1.202592 \\
\hline 3 & Import freight transportation & 0.458179 & 0.242783 & 0.751628 \\
\hline 4 & Transit freight transportation & 1 & 0.325897 & 1.640469 \\
\hline
\end{tabular}

According to the result, transit freight compared with other freight transportations, transportation is relatively efficient as which can be briefly interpreted as follows:

\section{Transit freight transportation $\geq$ export $\geq$ import $\geq$ domestic $O R$}

$$
1.00 \geq 0.73 \geq 0.46 \geq 0.23
$$

This means that export freight percent efficient. Based on the efficiency transportation efficiency is 73 percent. The calculation, we built the graphs and obtained less efficient freight transportation is domestic a much more precise efficiency measurement. transportation, which was measured as 23

\section{Graph 1: Weighted input and output}

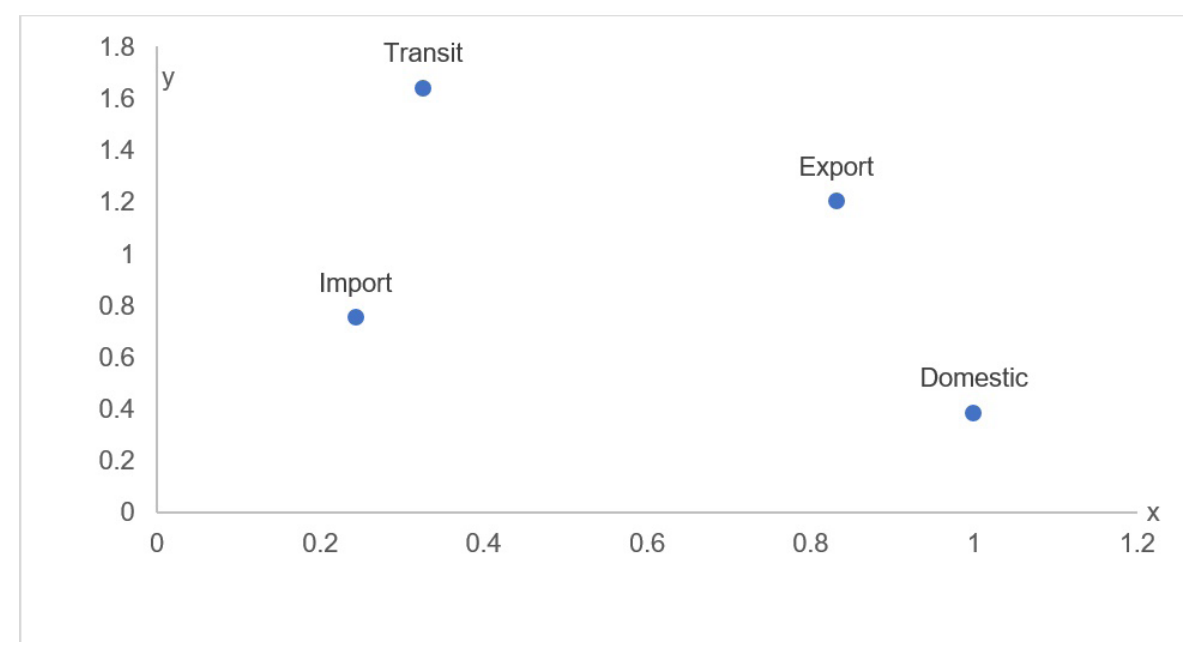




\section{Graph 2: Efficiency comparison}

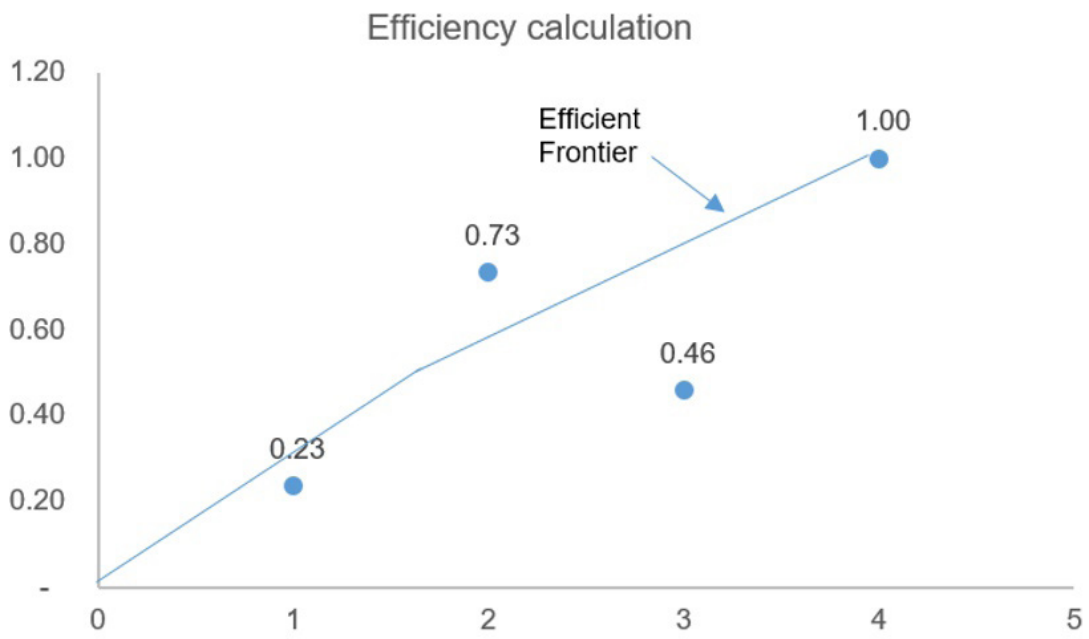

According to Graph 2, DMU1 or domestic freight transportation is not as inefficient. If we look at the efficient frontier line, it needs a slight improvement of input. The existing data on domestic freight railway transportation freight turnover and total route is comparatively higher than other DMUs, but according to DEA analysis, the transit transportation is more efficient than the rest of DMUs. Currently, Mongolia has only one central route which is $2100 \mathrm{~km}$ long running all the way from Beijing to Moscow crossing Ulaanbaatar. The actual length of the central railway route of
Mongolia is $1100 \mathrm{~km}$ [20, p. 93]. If our country builds the eastern region transit railway line, it would be shorter by $1000 \mathrm{~km}$ as compared to the existing central railway line. The total estimated eastern corridor route length is 1100 kilometers, which is three times shorter than the existing route from China to Russia. Apart from the information on efficiency score, DEA provides each inefficient unit with its corresponding benchmark. Moreover, the analysis could help find solution to improving on the inefficient units. 


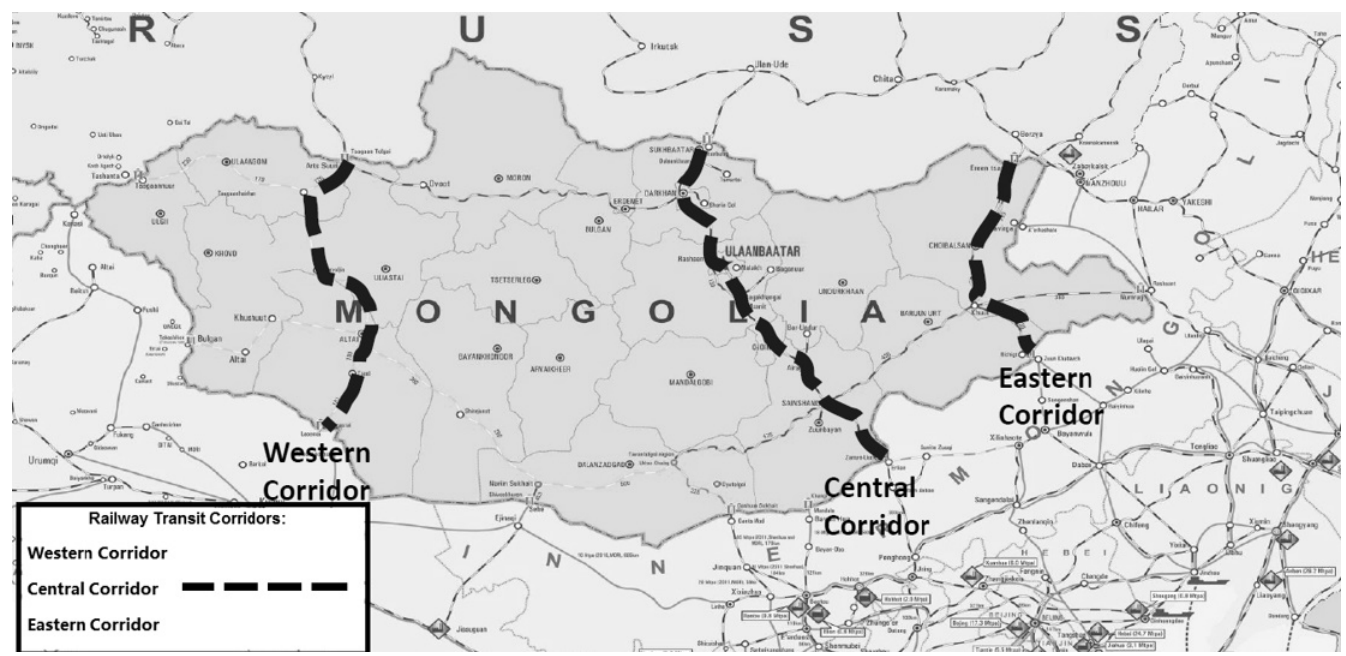

Figure 2: Proposed corridor on the Eastern and Western parts

Source:www.mrtd.gov.mn

\section{CONCLUSIONS}

In this paper, DEA model is proposed for evaluating the efficiency of DMUs with single input and single output. In addition, the analysis has used some numerical data which shows good performance. Data Envelopment Analysis is one of the best tools for the evaluation of any performance.

Efficiency is an important factor for the performance of all sectors and especially the transportation sector. In 2012, professor Francis Fukuyama had given a lecture at a forum, which organized under the auspices of the President of Mongolia. Prof. Fukuyama concluded his remarks by underlining that the development of a country need to protect its economy (economic security), politics, border and information. And more important "cooperation" [18]. With the help of modern transportation, countries can improve their foreign economic relations and even more, the country can also handle well such social challenges as migration, unemployment, rural development etc. UNCTAD has noted that "good policy drives progress". By providing evidence-based policy analysis, we can help countries improve on their economic, social and environmental outcomes [19]. B.
Otgonsuren has pointed out [17] that both the regional players need to create a joint working mechanism for the effective operation of the proposed economic corridor which crosses Russia, Mongolia and China. Schwab noted [6] that the Belt and Road initiative respects the differences between countries and their different paths of development, not imposing a specific plan or ideological framework, but seeking to create common ground for cooperation and mutual benefit. Transit transportation road is advantageous not only for Mongolia, Russia and China, it also important for all landlocked and developing countries. Thus, we need to promote and take advantage of the "One Belt One Road Initiative" in a much more efficient manner to gain access to the sea and get many more neighbours through the transit road.

Acknowledgement: This research paper was presented at INFORMS International meeting 2018 under the Transportation Session. We would like to express our deep gratitude to Professor Hou Yu Mei and professor Hu Hai $\mathrm{Ju}$ for their valuable suggestions and guidance. 


\section{REFERENCES}

[1] Gurjav Lombontseren, Our Scholars. Volume 11, "Mongolian market economy development and the Open model”, Ulaanbaatar: University of Science and Technology, 2004.

[2] E. Bayeh, "The Rights of Land-Locked States Under the International Law: The Role of Bilateral/Multilateral Agreements," Social Sciences, vol. 4, no. 2, p. 27, 2015.

[3] Xinhua News, "China, Russia, Mongolia endorse development plan on economic corridor".

[4] M. Alamgir, “Connecting Bangladesh: Economic Corridor Network," SSRN Electronic Journal, 2016.

[5] A. R. De Old, E. Sheets, and W. Alexander, Transportation: The Technology of Moving People and Products, An Nostrand Reinhold, 1986.

[6] Vivian Yang, "One Belt One Road: An Inclusive, Multistakeholder Model for Global Development".

[7] S. K. Soni, "China-Mongolia-Russia Economic Corridor: Opportunities and Challenges," in China's Global Rebalancing and the New Silk Road, B. R. Deepak, Ed. Singapore: Springer Singapore, 2018, pp. 101-117.

[8] Sodnomvanchig, G., and Avkhinsukh, J., Economic Geography of the Mongolian People's Republic, Ministry of People's Education, 1982.

[9] "Transforming Mongolia-Russia-China Relations: The Dushanbe Trilateral Summit | The Asia-Pacific Journal: Japan Focus.” [Online]. Available: https:/apjjf. org/2014/12/45/Alicia-Campi/4210.html. [Accessed: 20-Oct-2018].

[10] D. Bayarsaikhan, "Over 30 Projects Lined Up for Trilateral Economic Corridor," The UB Post, 29-Jun-2016.

[11] W. W. Cooper, L. M. Seiford, and J. Zhu, "Data Envelopment Analysis: History, Models, and Interpretations," Handbook on Data Envelopment Analysis, vol. 164, W. W. Cooper, L. M. Seiford, and J. Zhu, Eds. Boston, MA: Springer US, 2011, pp. 1-39.

[12] W. W. Cooper, L. M. Seiford, and K. Tone, Data envelopment analysis: a comprehensive text with models, applications, references and DEA-solver software, 2nd ed. New York: Springer, 2007.

[13] P. Andersen and N. C. Petersen, "A Procedure for Ranking Efficient Units in Data Envelopment Analysis," Management Science, vol. 39, no. 10, pp. 1261-1264, 1993.

[14] L. M. Seiford and J. Zhu, "Modeling undesirable factors in efficiency evaluation," European Journal of Operational Research, vol. 142, no. 1, pp. 16-20, Oct. 2002.

[15] "Ministry of Road and Transport Development of Mongolia".

[16] O. P. Hilmola, "European railway freight transportation and adaptation to demand decline: Efficiency and partial productivity analysis from period of 1980-2003," International Journal of Productivity and Performance Management, vol. 56, no. 3, pp. 205-225, 2007.

[17] Otgonsuren, B., "ERINA Report," Economic Research Institute for Northeast Asia, 127, Dec. 2015.

[18] Francis Fukuyama, Development model after world financial crisis, 2012.

[19] “CNUCED | Publications." [Online]. Available: https://unctad.org/fr/Pages/ publications.aspx. [Accessed: 20-Oct-2018].

[20] Mongolia. Montsame News Agency, 2006. 